\title{
AVANCES EN EL RECONOCIMIENTO DEL DERECHO HUMANO A LA IDENTIDAD DE GÉNERO AUTO-PERCIBIDA EN MÉXICO
}

\author{
Advances in the recognition of the human right to self-perceived \\ gender identity in Mexico
}

Miguel Ángel LEÓN ORTIZ

Sumario:

I. Introducción II. El resurgimiento de un fenómeno añejo: el transexualismo III. Los derechos de la personalidad: el carácter indivisible e interdependiente entre los derechos al libre desarrollo de la personalidad y la identidad personal IV ¿En qué consiste el derecho a la identidad de género auto-percibida? $V$. Tutela jurisprudencial del derecho a la identidad personal y de género VI. Constitucionalización del derecho a la identidad personal VII. Avances legislativos en torno al reconocimiento del derecho a la identidad de género auto-percibida en MéxicoVIII. Comentarios finales IX. Fuentes de consulta.

Resumen: El presente trabajo tiene como objetivo primordial identificar varios aspectos interesantes sobre el origen del fenómeno transexual en la historia contemporánea; de notoria influencia en la labor jurisdiccional nacional e internacional a través de la resolución de ciertos casos que han impactado la regulación de varios países. Desde el 2012, Argentina se convirtió en el primer país en el mundo en adoptar el criterio no patológico de las vivencias trans (que se registró por primera vez en los principios de Yogyakarta de 2006) con la publicación de la Ley No. 26743 de Identidad de Género, marcando una tendencia vanguardista en la garantización de los derechos de las diversidades de género en otros países del mundo que han elaborado disposiciones similares, incluyendo a México.

Palabras clave: Identidad de género, identidad personal, transexualidad, diversidades de género, derechos humanos.

Abstract: The main objective of this work is to identify several interesting aspects about the origin of the transsexual phenomenon in the contemporary history; of notorious influence on national and international jurisdictional work through the resolution of certain cases that have impacted the regulation of several countries. Since 2012, Argentina has become the first country in the world to adopt the non-pathological criterion of trans experiences (which was registered for the first time in the Yogyakarta principles of 2006) with the publication of Law No. 26743 of Gender Identity, marking an avant-garde trend in the guarantee of the rights of gender diversities in other countries of the world that have elaborated similar provisions, including México.

Key words: Gender identity, personal identity, transsexuality, gender diversities, human rights.

* Licenciado y Maestro en Derecho por la Universidad Nacional Autónoma de México, actualmente cursa el Doctorado Interinstitucional en Derecho (DID) en la Universidad Autónoma de Nayarit (UAN). 


\section{Introducción}

La diversidad de género es un rasgo característico de la especie humana que ha estado presente en diferentes períodos y civilizaciones de la historia. La novedad del asunto, es la forma cómo se concibe en la época contemporánea, primero desde el plano de las ciencias psiquiátrica, psicológica y médica y, posteriormente al trasladarse al terreno de las ciencias sociales y las humanidades.

A partir de la segunda mitad del siglo XX, el progresivo avance de la ciencia en el campo de la endocrinología, los tratamientos hormonales y las cirugías de reasignación genital inauguraron el episodio conocido como la medicalización transexual y, por ende, su caracterización patológica. Con el devenir de los años, el interés por su estudio se extendió a la planicie de las ciencias sociales, incluida la disciplina jurídica; gracias a ello, en los últimos años se han producido avances significativos en el reconocimiento del derecho a la identidad de género auto-percibida ${ }^{1}$ en los ámbitos legislativo y judicial.

Por esta razón, en este trabajo primero llevo a cabo un bosquejo preliminar sobre el origen del fenómeno transexual en la época contemporánea; más adelante, expreso en qué consisten los derechos de la personalidad, especialmente los derechos al libre desarrollo de la personalidad y a la identidad, y culminó con el análisis del derecho a la identidad de género, su contenido $\mathrm{y}$ avances en el orden legislativo y judicial nacional.

\section{El resurgimiento de un fenómeno añejo: el transexualismo}

Desde sus orígenes, la historia humana ha registrado diversas maneras de vivir el género en contextos y episodios muy variados; si bien el interés reciente por el fenómeno transexual ha sido producto del avance estrepitoso en el campo médico, principalmente en el rubro de la endocrinología y las cirugías de reasignación, cuya intención consiste en modificar los cuerpos, perpetrados hacia la segunda mitad del siglo XX.

La primera reflexión en torno al fenómeno transexual, al menos desde su vertiente médica, se registró en 1923, cuando Magnus Hirschfeld empleó por primera vez el término travestín en el ámbito de la sexología ${ }^{3}$ para aludir a una anomalía sexual diferente a la orientación homosexual, sugiriendo un abordaje científico distinto ${ }^{4}$. No obstante lo dicho, fue el psiquiatra y sexólogo estadounidense David O. Cauldwell, quien se encargó de acuñar el neologismo transexual 5 tras publicarse un artículo de su autoría en la Sexology Magazine en el año $1949^{6}$, refiriéndose a

\footnotetext{
${ }^{1}$ El documento denominado Los Principios de Yogyakarta de 2006 fue sugerente en el origen del término, en particular, el contenido del principio $3^{\circ}$, apartado $\mathrm{C}$, relativo al derecho al reconocimiento de la personalidad jurídica, al referirse a la adopción de medidas administrativas o legislativas tendientes a reflejar la identidad de género profunda que la persona define por y para sí, que después aparecería expresamente en el artículo $3^{\circ}$ de la Ley 26.743 de Identidad de Género en Argentina promulgada el 23 de mayo de 2012. Cfr. Saldivia MENAJOvsky, Laura (2017), Subordinaciones invertidas: sobre el derecho a la identidad de género, México, UNGS-UNAM, Instituto de Investigaciones Jurídicas, pp. 161 y 162.

${ }^{2}$ Aunque lo empleaba para referirse a estados transexuales.

${ }^{3}$ Meyerowitz, Joanne (2002), How sex changed. A history of transsexuality in the United States, Cambridge, Harvard University Press, p. 19.

${ }^{4}$ Cauldwell, David O. (1966), Trasvestismo. Hombres vestidos de mujer, trad. de Luis F. Rodríguez Molina, s.l.i. Manuales científicos, p. 8.

${ }^{5}$ En opinión de David O. Cauldwell las personas transexuales, son siempre travestis

6 Helien, Adrián y Piotto, Alba (2012), Cuerpxs equivocadxs: hacia la comprensión de la diversidad sexual, Argentina, Paidós, p. 185. En el mismo sentido, Lamas, Marta (2014), Cuerpo, sexo y política, México, Océano, p. 136. 
personas que a pesar de pertenecer físicamente a un sexo, buscan obtener la concordancia de los genitales a través de cirugías de cambio de sexo pues psíquicamente sienten pertenecer al sexo opuesto 7 .

La literatura especializada sobre el tema marca como su génesis el año 1953, tan pronto como fue publicado un artículo titulado Transvestism and transsexualism en el International Journal of Sexology $y^{8}$ por parte del médico y endocrinólogo estadounidense Harry Benjamin; científico encargado de difundir mundialmente el término transexualidad hacia la segunda mitad del siglo XX, tras darse a conocer la noticia sobre la exitosa modificación de la apariencia genital de George Jorgensen un año antes, la cual es narrada en el libro The transsexual phenomenon publicado en el año 1966.

Harry Benjamín asumió con bastante escepticismo las versiones que afirmaban que la transexualidad tenía un origen genético, al menos hasta que se hallarán indicios suficientes para respaldar esas afirmaciones, pues en su época las únicas desviaciones y anomalías sexuales eran clasificadas así por psicólogos y psiquiatras9. La relevancia de los trabajos de Harry Benjamin fue patente hasta la década de los ochenta, en especial mediante la Harry Benjamin Gender Disphoria Association; organismo encargado de elaborar los estándares que llevan su mismo nombre, los cuales siguen manteniendo gran influencia entre médicos y especialistas sobre el tema ${ }^{10}$. Años después, John Money y Robert Stoller ${ }^{11}$ concibieron la idea de los estados transexuales verdaderos por la presencia de disforia de género ${ }^{12}$, neologismo adjudicado a Norman Fisk para referirse al estado de angustia permanente que padecen las personas transexuales ${ }^{13}$.

John Money fue un psicólogo interesado por los estados intersex o hermafroditismo y la transexualidad. A él, le son adjudicados los neologismos gender role, gender identity y gender identity rol, con el propósito de descargar contenido linguístico a la palabra sexo, que por aquéllos años servía para describir indistintamente la diferenciación sexual y los comportamientos acordes con ese dimorfismo ${ }^{14}$. En su opinión, la educación de los padres durante la niñez tenía consecuencias en el desarrollo posterior del individuo, por lo que si la persona asumía una identidad de género diferente a la del dimorfismo genérico, existían indicios de trastornos postnatales de la diferenciación de la identidad de género ${ }^{15}$, o lo que es igual, un estado transexual verdadero ${ }^{16}$. En 1968 el médico y psicoanalista Robert J. Stoller estudió conductas sin anormalidades biológicas para diferenciar al transexualismo de los estados intersexuales por la presencia de sexos atípicos ${ }^{17}$, que hoy también son campo de investigaciones interdisciplinarias.

El punto álgido de estas bases teóricas fue incorporado al Diagnostic and Statistical Manual of Mental Disorders o Manual Diagnóstico y Estadístico de los Trastornos Mentales en su ver-

\footnotetext{
7 Mercader, Patricia (1997), La ilusión transexual, trad. de Paula Mahler, Argentina, Nueva visión, p. 43.

8 Ibídem, p. 44.

9 Benjamin, Harry (1999), The transsexual phenomenon, Düsseldorf, Symposium publishing, p. 7.

${ }^{10}$ Mercader, Patricia (1997), op. cit. nota 7, p. 52.

${ }^{11}$ Las ideas centrales de Robert Stoller pueden verse en su libro The Transsexual Experiment, en el cual específica de forma más precisa el diagnóstico del estado transexual verdadero. Véase, MISSÉ, Miquel (2014), Transexualidades. Otras miradas posibles, Madrid, España, Egales, p. 34.

${ }^{12}$ Frignet, Henry (2003), El transexualismo, trad. de Horacio Pons, Argentina, Nueva visión, pp. 19-21.

${ }^{13}$ Lameiras Fernández, María et. al. (2013), Sexualidad y salud: el estudio de la sexualidad humana desde una perspectiva de género, España, Universidad de Vigo-Servizo de Publicacións, p. 204.

${ }^{14}$ Money, John y Ehrhardt, Anke A. (1982), Desarrollo de la sexualidad humana. diferenciación y dimorfismo de la identidad de género desde la concepción hasta la madurez, trad. de A. Guerra Miralles, España, Morata, p. 5

${ }^{15}$ Ibídem, p. 34 .

${ }^{16}$ Mercader, Patricia (1997), op. cit., nota 7, pp. 54 y 55.

${ }^{17}$ Lamas, Marta (2014), Cuerpo, sexo y política, México, Océano-Debate feminista, p. 137.
} 
sión III del año 1980 (DSM-III por sus siglas en inglés), elaborado por la American Psychiatric Association y, a la International Statistical Classification of Diseases and Related Health Problems en su décima versión de 1992 (en adelante CIE-10) de la World Health Organization u Organización Mundial de la Salud (OMS), estatuyéndose la lectura patológica de las vivencias trans en el plano clínico de la psiquiatría. El primer documento, la concibió como una desviación $n^{18}$; el segundo lo hizo para referirse a un trastorno de la identidad sexual ${ }^{19}$, pero ambas bajo un mismo denominador: calificar como enfermedades a las diversidades para disciplinarlas a la categoría binaria de sexo cuando no hay correspondencia con las identidades genéricas femenina o masculina ${ }^{20}$.

Las siguientes décadas trajeron una oleada de ideas, teorías y trabajos elaborados por investigadoras feministas, organizaciones y activistas norteamericanas, impulsando el paradigma transgender en los años noventa, que vino a cuestionar el criterio patológico de las diversidades de género cimentado por las disciplinas médica y psicológica con base en los postulados de Harry Benjamin, John Money y Robert Stoller, principalmente. Así, la contribución de los estudios de las ciencias sociales restó importancia a las bases médicas y psiquiátricas sobre el transexualismo, resaltando el papel de la autonomía en la definición de la identidad.

En este escenario, resultó crucial la aportación de las psicólogas Suzanne Kessler y Wendy McKenna, quienes al publicar el libro Gender: An ethnomethodological approach, en el año 1978, cuestionaron las etiquetas binarias de sexo y género resaltando el lugar que ocupa el factor socio-cultural en la construcción individual de la identidad de género. Y lo mismo ocurrió al publicarse el libro Transgender Liberation: A movement whose time has come, de la activista Leslie Feinberg en 1992, o The empire strikes back: A posttranssexual Manifesto de Sandy Stone un año antes, cuya propuesta consistió en asumir la identidad de género diversa sin necesidad de acudir al intervencionismo de los cuerpos ${ }^{21}$. A la postre, incitadoras del nacimiento del paradigma no patológico de las vivencias trans, de notoria influencia para el derecho en los últimos años.

\section{Los derechos de la personalidad: el carácter indivisible e interdependiente entre los derechos al libre desarrollo de la personalidad y a la identidad personal}

\section{Los derechos de la personalidad}

El reconocimiento de los llamados derechos de la personalidad, cimentó el respeto por los bienes esenciales de cada individuo perteneciente a la especie humana en su carácter de sujeto titular de derechos digno de tutela jurídica ${ }^{22}$. Estos derechos pueden ser definidos como aquellos

\footnotetext{
${ }^{18}$ Entendiéndose por tal la Desviación sexual centrada en la creencia fija de que los caracteres sexuales externos no son los que corresponden a la persona. La conducta resultante se dirige ya sea hacia el cambio de los órganos sexuales por medio de operación quirúrgica o hacia el ocultamiento completo del sexo aparente adoptando el vestido y los modales del sexo opuesto.

${ }^{19}$ Definiendo al transexualismo como un trastorno de identidad sexual consistente en el deseo de vivir y de ser aceptado como un miembro del sexo opuesto, que suele acompañarse por sentimientos de malestar o desacuerdo con el sexo anatómico propio y de deseos de someterse a tratamiento quirúrgico u hormonal para hacer que el propio cuerpo concuerde lo más posible con el sexo preferido.

${ }^{20}$ Saldivia Menajovsky, Laura (2017), op. cit., nota 1, p. 52

${ }^{21}$ Lamas, Marta (2012), “Transexualidad: ¿el estudio de lo extraño?”, en Parrini Roses, Rodrigo (coord.), Los archivos del cuerpo: ¿Cómo estudiar el cuerpo?, México, UNAM, Programa Universitario de Estudios de Género, p. 224.

${ }^{22}$ Galindo Garfias, Ignacio, (2010), Derecho civil. Primer curso: parte general, personas, familia, México Porrúa, pp. 322 y 323.
} 
que son la esencia misma de la persona en su calidad de ser humano ${ }^{23}$. El interés por su estudio se remonta al período que siguió a la Segunda Guerra Mundial, convirtiéndose la persona en el fin primordial para los emergentes Estados constitucionales de derecho.

La base para el reconocimiento y protección de los derechos de la personalidad es el respeto por la dignidad humana, prevista en el artículo primero de la Declaración Universal de los Derechos Humanos al proclamar que todos los seres humanos nacen libres e iguales en dignidad $y$ derechos $y$, dotados como están de razón y conciencia, deben comportarse fraternalmente los unos con los otros.

Estos derechos, son un subconjunto de una clasificación más amplia: la de los derechos humanos $^{24}$; esenciales para que el individuo pueda identificarse en la vida diaria y trazar el proyecto de vida que se ajuste con sus convicciones, valores, principios y creencias personales, mediante el ejercicio de las prerrogativas y garantías que se tienen para hacerlos efectivos, pero sin transgredir los derechos de terceros.

Para otra posición de la doctrina, es difícil precisar la distinción entre los llamados derechos de la personalidad y los derechos humanos, sin embargo parece ser una cuestión de índole histórico en la que los primeros ha sido producto de la evolución de las teorías civilistas de tradición jurídica romanista, siendo los segundos producto del movimiento del constitucionalismo, importante en la construcción del discurso de los derechos humanos y las bases del neoconstitucionalismo como doctrina y metodología jurídicas.

Así, podría decirse que hubo un origen paralelo entre ambas construcciones teóricas, siendo la doctrina de los derechos humanos la que predominó tras la finalización de los dos grandes conflictos bélicos mundiales, integrando un número indeterminado de prerrogativas en los diversos documentos internacionales en materia de derechos humanos donde también fueron incluidos aquellos. Con ello, se logro configurar un nuevo episodio político mundial, la configuración de Estados constitucionales de derecho garantes de la protección de los derechos de las personas contra los abusos y excesos de los órganos estatales con base en el principio de la dignidad humana, exigibles ante organismos nacionales y supra-nacionales en virtud de su caracterización abstracta y universal; dejando en manos de la jurisdicción civil la función de estatuir mecanismos e instrumentos para hacerlos efectivos en las esferas administrativa y jurisdiccional en el orden interno, dada su caracterización concreta ${ }^{25}$.

De este modo, los derechos al libre desarrollo de la personalidad y a la identidad personal -que incluye el derecho a la identidad de género- forman parte de los derechos de la personalidad, cuya estrecha conexión con otros de la misma naturaleza resulta primordial para su entera satisfacción.

\footnotetext{
${ }^{23}$ Ibídem, p. 324.

${ }^{24}$ VÁsquez Mellado García, Julio César (2017), "Nueva acta de nacimiento: un derecho de las minorías (transexuales)", en: Valls Esponda, Guillermo y Valls Esponda, Sergio Arturo (coords.), Tiempo de justicia: voces responsables: estudios en homenaje a Sergio Valls Hernández, México, SCJN, pp. 1047 y 1048.

${ }^{25}$ Por ejemplo, en la Ciudad de México existe una base normativa para reclamar la reparación del daño a través de la Ley de responsabilidad civil para la protección de la vida privada, el honor y la propia imagen, y hace pocos años se añadió el procedimiento administrativo para reconocer el derecho a la identidad de género en el Código Civil y en el Reglamento del Registro Civil citadinos.
} 


\subsection{El derecho al libre desarrollo de la personalidad}

En nuestro país, hasta antes de la incorporación del derecho a la identidad de género en el código civil del entonces Distrito Federal en el año 2008 y, el posterior reconocimiento del derecho humano a la identidad personal en el artículo $4^{\circ}$ de la Constitución Política de los Estados Unidos Mexicanos en el año 2014, el derecho al libre desarrollo de la personalidad se convirtió en la fórmula jurídica para exigir del Estado el reconocimiento de este derecho, tal como lo asentó la Primera Sala de la Suprema Corte de Justicia de la Nación (SCJN), en los términos siguientes:

Cuando un determinado "espacio vital" es intervenido a través de una medida estatal y no se encuentra expresamente protegido por un derecho de libertad específico, las personas pueden invocar la protección del derecho al libre desarrollo de la personalidad. De esta manera, este derecho puede entrar en juego siempre que una acción no se encuentre tutelada por un derecho de libertad específico ${ }^{26}$.

El derecho al libre desarrollo de la personalidad es definido por la SCJN como el reconocimiento del Estado sobre la facultad natural de toda persona a ser individualmente como quiere ser, sin coacción ni controles injustificados, con el fin de cumplir las metas u objetivos que se ha fijado, de acuerdo con sus valores, ideas, expectativas, gustos, etcétera ${ }^{27}$. Se trata, en última instancia, de la facultad para elegir en forma libre y autónoma el proyecto de vida. Sin él no sería posible la materialización de otros importantes derechos, como lo es el derecho a la identidad personal, pues al restringirse la potestad para que el sujeto elija el proyecto de vida que permita cumplir con su proyecto de vida con base en la autonomía, creencias y convicciones personales, sería imposible ejercer otras prerrogativas. Y ello, también es congruente con lo establecido por la Corte Interamericana de Derechos Humanos (CIDH), al expresar que de la tutela de este derecho se desprende que cada persona es libre y autónoma de seguir un modelo de vida de acuerdo con sus valores, creencias, convicciones e intereses ${ }^{28}$.

La dificultad para establecer una definición más o menos compartida en el ámbito legislativo y doctrinal, ha sido subsanada por el juzgador al fijar el contenido y alcances de este derecho a pesar del vacío existente en la normatividad nacional. En este terreno, Colombia ha realizado una importante labor jurisprudencial bajo el denominador libertad de acción o cláusula general de libertad para decidir el plan de vida que corresponda con las creencias y convicciones de cada persona $^{29}$, cimentada en la dignidad humana como ya quedó asentado por la Corte mexicana en la tesis P.LXVI/2009.

Por tal motivo, al tratarse de la esfera de actuación individual, la identidad personal entendida como la dimensión más intrínseca y original de la persona, o las claves que le permiten comprenderse a sí misma y entender su lugar en el mundo ${ }^{30}$, se encuentra estrechamente entrelazado

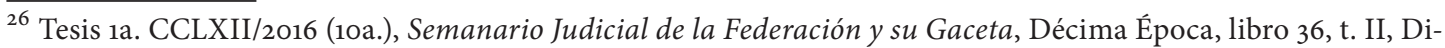
ciembre de 2016, p. 896.

27 Tesis P. LXVI/2009, Semanario Judicial de la Federación y su Gaceta, Novena Época, t. XXX, Diciembre de 2009, p. 7.

${ }^{28}$ OC-24/17, p. 45.

${ }^{29}$ LozAno Villegas, Germán (2004), "El libre desarrollo de la personalidad y cambio de sexo: el transexualismo”, en: Carbonell, Miguel (Coord.), Derecho constitucional. Memoria del Congreso Internacional de Culturas y Sistemas Jurídicos Comparados, México, UNAM, Instituto de Investigaciones Jurídicas, p. 629.

30 Aparisi Miralles, Ángela (2011), “Derecho a la identidad (jurídico)”, en: Romeo Casabona, Carlos María (dir.), Enciclopedia de Bioderecho y Bioética, España, Comares, t. I (a-h), p. 538.
} 
con el derecho al libre desarrollo de la personalidad, tal como lo ha precisado el Pleno de la SCJN, en los términos siguientes:

Partiendo de que el derecho al libre desarrollo de la personalidad implica necesariamente el reconocimiento a los derechos a la identidad personal, sexual y de género, pues a partir de éstos el individuo se proyecta frente a sí mismo y dentro de una sociedad, se concluye que la reasignación sexual que decida una persona transexual para adecuar su estado psicosocial a su físico y de ahí, vivir en el sexo con el que se identifica plenamente y ser reconocido como tal por los demás, constituye una decisión que forma parte del libre desarrollo de la personalidad, en tanto es una expresión de la individualidad de la persona, respecto de su percepción sexual y de género ante sí mismo, que influye decisivamente en su proyecto de vida y en todas sus relaciones dentro de la sociedad ${ }^{31}$.

\section{2. ¿Qué es la identidad personal y porque es importante su tutela jurídica?}

Todo ser humano, en tanto constituye una unidad material y espiritual, reúne una serie de atributos, elementos esenciales y complejos que al final permiten distinguirlo de los demás, haciendo de él un ser único en el planeta capaz de construir una biografía propia. De ahí la relevancia de su tutela jurídica ${ }^{32}$.

La literatura jurídica latinoamericana ha sido impregnada por las ideas desarrolladas por la jurisprudencia italiana en torno al concepto, contenido y alcance de este derecho. Uno de los primeros juristas en definirla fue el peruano Carlos Fernández Sessarego, para quien la identidad personal es el conjunto de atributos y características que permiten individualizar a la persona en sociedad. Identidad personal es todo aquello que hace que cada cual sea "uno mismo" y no "otro"33. Esta definición, si bien representó un esfuerzo notable por desentrañar el contenido básico de la identidad, pose un tamiz puramente cuantitativo, pues se limita a enumerar los rasgos o elementos que la componen pero no describe la naturaleza del concepto.

En años recientes, se han configurado otras definiciones de índole cualitativa que describen con mayor claridad en qué consiste la identidad, una de ellas es postulada por la argentina Junyent Bas de Sandoval, al decir que significa no solamente conocer nuestro origen biológico. Implica además elegir dentro de nuestro ser persona, un ser de tal manera, con particularidades potenciales, ideas políticas, religiosas, intelectuales, éticas y humanas; ser uno mismo y no otro ${ }^{34}$.

Da esta forma, la identidad personal reúne dos aspectos complementarios: la parte externa y la parte interna. La primera abarca ciertos aspectos dados, ya sea por la naturaleza o por el entorno medioambiental, dentro de éstos se pueden mencionar el nombre, el sexo, la raza, la etnia, el núcleo familiar, la nacionalidad y los rasgos físicos, su peculiaridad es que no son elegidos por el individuo, pero a partir de ellos el individuo comienza a tomar conciencia de sí mismo; la segunda, engloba el conjunto de elementos adquiridos por cada sujeto a lo largo de la vida, como son: el contexto social y cultural los cuales son intra-psíquicamente valorados, permitiendo

\footnotetext{
${ }^{31}$ Tesis P. LXIX/2009, Semanario Judicial de la Federación y su Gaceta, Novena Época, t. XXX, Diciembre de 2009, p. 17.

32 Fernández Sessarego, Carlos (1992), Derecho a la identidad personal, Buenos Aires, Argentina, Astrea, p. 15.

${ }^{33}$ Ibídem, p. 113.

34 Junyent Bas De Sandoval, Beatriz María (2016), Fecundación asistida e identidad personal, Buenos Aires, Argentina, Astrea, p. 23.
} 
estar en posibilidad de elegir una historia marcada por las creencias, convicciones éticas, religiosas y políticas de cada persona, recreándose día a día ${ }^{35}$, distinguiendo el yo soy del yo no soy.

De esta manera, si bien el elemento externo tiene un efecto decisivo en la definición de la identidad, el aspecto interno ocupa un papel primordial en la construcción de la individualidad. Al respecto, el Pleno de la Corte ha establecido lo siguiente:

Ante los factores objetivos y subjetivos que definen a una persona, se advierte que tratándose de su identidad sexual y de género, se presenta en la realidad una prelación o preeminencia del factor subjetivo (sentimientos, proyecciones, ideales), sobre sus caracteres físicos o morfológicos (factor objetivo), de manera que derivado de la compleja naturaleza humana, que lleva a cada individuo a desarrollar su propia personalidad con base en la visión particular que respecto de sí mismo tenga, debe darse un carácter preeminente al sexo psicosocial frente al morfológico, a fin de respetar plenamente los derechos de identidad sexual y de género de una persona transexual, al ser aspectos que, en mayor medida, definen tanto la visión que la persona tiene frente a sí misma como su proyección ante la sociedad ${ }^{36}$.

Por todo lo dicho, podríamos decir que el derecho a la identidad personal puede ser definido como:

el derecho humano y personalísimo que tiene cada niño, cada persona, a ser lo que es y ejercer libremente la capacidad del autoconocimiento integral, incluyendo el acceso a la verdad sobre sus raíces y la autodeterminación de su personalidad en todas sus facetas: social, cultural, intelectual, política, sexual, etc., siempre que sean axiológicamente válidas para el ordenamiento jurídico ${ }^{37}$.

Para concluir este apartado, es pertinente decir que la tutela de este derecho protege la mismidad, reconociendo la individualidad de cada persona sin distorsionar los atributos y características que la definen. Además, es importante porque permite establecer relaciones jurídicas entre personas con un nombre, sexo, familia, raza, etnia, nacionalidad, etcétera, protegiendo el proyecto individual que cada quien elija ${ }^{38}$.

\section{IV. ¿En qué consiste el derecho a la identidad de género auto-percibida?}

Si partimos de la asociación irrefutable del binomio sexo-género para entender que la construcción de nuestra identidad se produce a partir de ciertos factores externos de orden biológico y medioambiental que el individuo no elige, los cuales se relacionan con otros de orden interno o psico-socio-culturales ${ }^{39}$, es posible comprender que existen diversas formas de asumir la identidad de género en la especie humana.

El sexo, entendido como un conjunto de factores de orden cromosómico, gonadal, hormonal y morfológico, configuró por muchos años la ideología de los dos sexos sobre la base de un

\footnotetext{
35 Aparisi Miralles, Ángela (2011), op. cit., nota 30, p. 538.

${ }^{36}$ Tesis P. LXXI/2009, Semanario Judicial de la Federación y su Gaceta, Novena Época, t. XXX, Diciembre de 2009, p. 20.

37 Junyent Bas De Sandoval, Beatriz María (2016), op. cit., nota 34, p. 41.

${ }^{38}$ López Serna, Marcela Leticia y Kala, Julio César (2018), "Derecho a la identidad personal, como resultado del libre desarrollo de la personalidad”, en: Revista Ciencia Jurídica, México, año 7, Núm. 14, pp. 68-69.

39 Camps Merlo, Marina (2007), Identidad sexual y derecho. Estudio interdisciplinario del transexualismo, España, EUNSA, pp. 286-287.
} 
dispositivo de poder de orden patriarcal que dictó estereotipos de conducta basados en esa diferenciación sexual, produciéndose lo que John Money calificaría como el dimorfismo de género, en el que la naturaleza, la herencia y el medio ambiente interactúan durante un período crucial del desarrollo. El correspondiente efecto es aumentado mediante subsiguientes interacciones, hasta que el producto final queda fijado permanentemente ${ }^{40}$.

Este dispositivo heteronormativo, como señala Núñez Noriega, es conocido como el poder de nominación o de representación, el cual permite encasillar la realidad mediante representaciones ideadas por los detentadores de poder, estableciendo un sistema de control sobre los comportamientos de los individuos e incluso sobre las transformaciones de esa realidad ${ }^{41}$. Por ejemplo, enclavando en el imaginario social la idea de la necesidad de intervenir los cuerpos diversos para ajustarlos al modelo de los cuerpos heteronormados.

Con la adhesión del factor psico-social a la definición del sexo, se perfilo la teoría del sexo psico-social, relevante para comprender la forma como el plano interior o subjetivo resulta primordial en la conformación de la identidad de género ${ }^{42}$, teorización que permitió trazar la definición de identidad de género que aparece en los Principios de Yogyakarta de 2006, en los términos que siguen:

La identidad de género se refiere a la vivencia interna e individual del género tal como cada persona la siente profundamente, la cual podría corresponder o no con el sexo asignado al momento del nacimiento, incluyendo la vivencia personal del cuerpo (que podría involucrar la modificación de la apariencia o la función corporal a través de medios médicos, quirúrgicos o de otra indole, siempre que la misma sea libremente escogida) y otras expresiones de género, incluyendo la vestimenta, el modo de hablar y los modales ${ }^{43}$.

Argentina fue el primer país en el mundo en elaborar un proyecto legislativo que adoptó el criterio no patológico de las vivencias trans, impulsado por un aparato intelectual producto de la añadidura de las ciencias sociales a la indagación del tema que emergió desde la década de los noventas, donde figuras como Wendy McKenna, Suzanne Kessler, Anne Fausto Sterling, Leslie Feinberg, Susan Striker, Judith Butler y Sandy Stone trazaron nuevas ideas, referentes teóricos y conceptuales en torno al tema, luego bien recibidas por organizaciones defensoras de los derechos de la población trans bajo la campaña a la que se denominó Stop Trans Pathologization 2012 o STP-2012, gestada en España y Francia en el año 2009, cuestionando el predominio del paradigma patológico ceñido a partir del proceso de medicalización del fenómeno transexual ${ }^{44}$.

De esta forma, el 23 de mayo de 2012 fue promulgada la Ley No. 26743 de Identidad de Género, la cual sentó las bases de un modelo legislativo incluyente con las diversidades de género

\footnotetext{
${ }^{40}$ Money fijo las bases para entender el rol diferenciador entre varón y mujer desde el punto de vista biológico y la relación ineludible con el factor psico-sexual en la configuración de comportamientos y actitudes de género correspondientes con el dimorfismo de género. Cfr. MONEY, John y EHRHARDT, Anke A. (1982), op. cit., nota 14 , p. 8.

${ }^{41}$ NúÑ̃ez Noriega, Guillermo (2016), ¿Qué es la diversidad sexual?, México, Ariel-CIAD-UNAM, Programa Universitario de Estudios de Género, pp. 34 y 35.

42 Kemelmajer De Carlucci, Aída y LAMM, Eleonora (2010), "La persona transexual, menor de edad competente para decidir sobre la intervención médica que requiere judicialmente”, en: Diversidad sexual, Argentina, Lugar-APA, pp. 187-188.

${ }^{43}$ Principios de Yogyakarta, Marzo de 2007, p. 8, [en línea], disponible en: https://www.refworld.org/cgi-bin/texis/ vtx/rwmain/opendocpdf.pdf?reldoc=y\&docid=48244egf 2 (consultado el 23 de mayo de 2018).

${ }^{44}$ Araneta Zinhunegi, Aitzole (2017), "Transfronteras: un nuevo activismo mundial por la despatologización trans", en: Moreno Cabrera, Octavio y Puche Cabezas, Luis (eds.), Transexualidad, adolescencias y educación: miradas multidisciplinares, 2a. ed. Madrid, España, Egales, p. 89.
} 
al reconocer el carácter diverso de la especie humana más allá del modelo hegemónico heterosexista. Esta nueva perspectiva jurídica, abrió un nuevo episodio en el reconocimiento de este derecho a nivel regional e internacional, creando un modelo jurídico no patológico sin necesidad de acudir ante una instancia judicial o administrativa para obtener el reconocimiento del derecho. De ahí, que en años recientes este paradigma se esté extendiendo a varios países en el mundo, como ya sucedió en Noruega ${ }^{45}$, Malta ${ }^{46}$, España ${ }^{47}$, Uruguay ${ }^{48}$ o Chile ${ }^{49}$.

Desde el punto de vista estricto, el reconocimiento de este derecho en la legislación Argentina implicó tres aspectos esencialmente:

1.- El reconocimiento sustancial del derecho en el orden jurídico interno;

2.- La materialización del derecho a partir de la efectiva tutela del derecho al libre desarrollo de la personalidad, $\mathrm{y}$

3.- Un trato respetuoso y congruente con la identidad de género ${ }^{50}$.

Desde un punto de vista amplio, Saldivia Menajovsky ${ }^{51}$, expresa que fueron cuatro los aspectos:

$1^{\circ}$. Arrebatar de las autoridades judicial y administrativa la facultad para reconocer la identidad de género auto-percibida;

$2^{\circ}$. Reconocer autonomía plena al sujeto para decida libremente sobre el uso de tratamientos hormonales o cirugías de reasignación genital. Aquí es pertinente expresar la relevancia de manifestar el consentimiento libre e informado, entendido como un proceso primordial de contenido ético a partir del cual, el paciente, con base en el principio de autonomía, tiene el poder para decidir sobre el uso o no de cualquier tratamiento o intervención médica que involucre su bienestar físico y emocional previa explicación detallada sobre la naturaleza procedimental del mismo;

$3^{\circ}$. Reconocer el derecho a los menores de edad en sintonía con la Convención sobre los Derechos del Niño de 1989 y el Código Civil y Comercial de 2014, a fin de que el infante pueda participar en la toma de decisiones que involucren su bienestar y salud de conformidad con el grado de desarrollo de la autonomía siendo el acompañamiento de los padres un elemento fundamental, y

${ }^{45}$ La Lov om endring av juridisk Kjonn Noruega del año 2016 reconoció este derecho también a los infantes.

${ }^{46}$ Con la publicación de la Act No. XI de 14 de abril de 2015.

47 A partir de la promulgación de leyes sobre la materia en las Comunidades Autónomas de Andalucía (2014), Extremadura (2015), Madrid (2016) y Aragón (2018).

${ }^{48}$ El o7 de noviembre de 2018 fue publicada en el Diario Oficial uruguayo la Ley 19.684 Integral para Personas Trans, abrogando la Ley 18.620 sobre el Derecho a la Identidad de Género y al Cambio de Nombre y Sexo en Documentos Identificatorios de 17 de noviembre de 2009.

49 El 10 de diciembre de 2018 fue publicada en el Diario Oficial chileno la Ley número 21.120 que Reconoce y da Protección al Derecho a la Identidad de Género, limitando el derecho a mayores de 14 años (art. 12). Esta ley dejo sin efecto a las Leyes número 17.344 que autoriza el Cambio de Nombre y Apellidos de 22 de septiembre de 1970 y la 4.808 que reforma la Ley sobre Registro Civil de 10 de febrero de 1930.

50 Saldivia Menajovsky, Laura (2017), op. cit., nota 1, pp. 132.

${ }^{51}$ Saldivia Menajovsky, Laura (2018), “La bioética despatologizadora del derecho a la identidad de género", en: Bioética laica: vida, muerte, género, reproducción y familia, México, UNAM, Instituto de Investigaciones Jurídicas, pág. 138 . 
$4^{\circ}$. Elimina cualquier requisito para acreditar el empleo de terapias, hormonas o cirugía de reasignación genital, sin que por tal razón se pueda negar el acceso a dichos procedimientos, al formar parte del catálogo de servicios de seguridad social en Argentina.

Sin duda, este nuevo modelo jurídico, además de reconocer el derecho a la identidad de género auto-percibida, antepone el respeto por otros derechos fundamentales, como son: el derecho al libre desarrollo de la personalidad, el derecho a la igualdad, el derecho a la no discriminación y el derecho a la salud. También, supone un acierto notable en términos éticos, al modificar la relación médico-paciente en la posibilidad de modificar el cuerpo ${ }^{52} \mathrm{y}$, aunque sigue manteniendo algunos aspectos del binarismo de género, por ejemplo al no referirse a los estados intersex, la ley representa un duro revés al modelo cultural de los dos géneros ${ }^{53}$.

\section{Tutela jurisprudencial del derecho a la identidad personal y de género}

La labor de la SCJN en la tutela del derecho a la identidad personal y de género ha sido evidente. Primeramente, definiendo el derecho a la identidad en los términos siguientes:

El derecho de todo individuo a ser uno mismo, en la propia conciencia y en la opinión de los demás, es decir, es la forma en que se ve a sí mismo y se proyecta en la sociedad, de acuerdo con sus caracteres físicos e internos y sus acciones, que lo individualizan ante la sociedad y permiten identificarlo ${ }^{54}$...

En ella, la Corte resalto los dos componentes precisados en apartados anteriores: el aspecto interno y externo; interrelacionando la apropiación de los factores biológicos como son los fisiológicos y anatómicos, con la forma en que cada persona se percibe a sí misma. De ahí a la fecha, la SCJN ha elaborado diferentes criterios para resolver ciertos asuntos relativos al reconocimiento del derecho a la identidad de género, sobresaliendo los siguientes:

$1^{\circ}$. Reasignación sexual. Preeminencia del sexo psico-social frente al morfológico para respetar a plenitud los derechos de identidad sexual y de género de una persona transexual (P. LXXI/2009);

$2^{\circ}$. Reasignación sexual. Es una decisión que forma parte de los derechos al libre desarrollo de la personalidad (P. LXIX/2009);

$3^{\circ}$. Reasignación sexual. No existe razonabilidad para limitar los derechos fundamentales de una persona transexual, impidiéndole la adecuación de sus documentos de identidad, bajo el pretexto de preservar derechos de terceros o el orden público (P. LXXIV/2009);

$4^{\circ}$. Reasignación sexual. Necesaria expedición de nuevos documentos de identidad (P. LXX/2009);

$5^{\circ}$. Identidad de género auto-percibida. Procedimiento idóneo para obtener la identidad de género es el administrativo (1a. CCCXXXIV/2018), y

\footnotetext{
${ }^{52}$ Ibídem, p. 145.

${ }^{53}$ Menin, Francisco J. (2015), "La identidad de género como derecho humano: la legislación argentina”, Anuario de Derecho Constitucional, Colombia, año XXI, pp. 634-635.

54 Tesis P. LXVII/2009, Semanario Judicial de la Federación y su Gaceta, Novena Época, t. XXX, diciembre de 2009, p. 7.
} 
$6^{\circ}$. Identidad de género auto-percibida. Inconstitucionalidad del procedimiento judicial para tramitar la reasignación de la identidad sexo genérica en el Estado de Veracruz es inconstitucional (1a. CCXXXI/2018).

La CIDH, también lo definió en los términos siguientes:

El conjunto de atributos y características que permiten la individualización de la persona en sociedad y que, en tal sentido, comprende varios derechos según el sujeto de derechos de que se trate y las circunstancias del caso. El derecho a la identidad puede verse afectado por un sinnúmero de situaciones o contextos que pueden ocurrir desde la niñez hasta la adultez ${ }^{55}$.

Esta otra definición, también distingue los componentes de la identidad, aunque lo hace de forma genérica (atributos y características), resaltando el carácter abstracto de tal derecho para que sean los jueces quienes se encarguen de esgrimir su contenido de acuerdo con las circunstancias de cada asunto.

\section{Constitucionalización del derecho a la identidad personal}

El 17 de junio de 2014, fue publicado en el Diario Oficial de la Federación un decreto de reforma para añadir el párrafo octavo al contenido del artículo $4^{\circ}$ de la Constitución federal, mismo que a continuación se reproduce:

Toda persona tiene derecho a la identidad y a ser registrado de manera inmediata a su nacimiento. El Estado garantizará el cumplimiento de estos derechos. La autoridad competente expedirá gratuitamente la primera copia certificada del acta de registro de nacimiento.

Con dicha reforma, se reconoció el derecho fundamental a la identidad personal desde el mismo plano constitucional, desprendiéndose el deber del Estado mexicano para definir los mecanismos para salvaguardar su entera protección en las normas secundarias del sistema jurídico nacional.

En el plano local, la Constitución Política de la Ciudad de México de 05 de febrero de 2017 instauró una serie de prerrogativas para proteger los derechos de la población trans. En primer lugar, añadiendo la categoría identidad de género a la cláusula de no discriminación estipulada en el artículo $4^{\circ}$, apartado C, numeral 2; en segundo término, a través del reconocimiento del derecho a la identidad jurídica en el artículo $6^{\circ}$, apartado $C$, numerales 1 y 2 , garantizando el derecho de fácil acceso en la emisión de los documentos de identidad; $y$, en tercer lugar, al reconocer los derechos del colectivo LGBTTTI en el artículo 11, apartado H, con la finalidad de garantizar atención prioritaria a personas y grupos en situación de vulnerabilidad como ocurre con la población trans.

Es bien sabido que dentro de la cultura jurídica occidental, el derecho a la identidad se encuentra implícitamente previsto en ciertos documentos internacionales que reconocen el derecho a poseer un nombre ${ }^{56}$; derecho humano y atributo de la personalidad de cualquier titular de derechos que puede ser definido como el conjunto de letras o vocablos que sirven para de-

\footnotetext{
55 OC-24/17, p. 45.

${ }^{56}$ Así lo hacen, el Pacto Internacional de Derechos Civiles y Políticos de 1966 en el artículo 24, apartado 2, y la Convención Americana de los Derechos Humanos de 1948 en el artículo 18.
} 
signar e identificar a una persona ${ }^{57}$, siendo la Convención sobre los Derechos del Niño de 1989 el único que se refiere expresamente a él como derecho a la identidad en sus artículos $7^{\circ}$ y $8^{\circ}$. Sin embargo, este derecho no debe confundirse con el derecho a poseer una identidad jurídica pues, siendo éste último el género, no sólo comprende al nombre sino al resto de atributos de la personalidad (domicilio, capacidad, nacionalidad, estado civil), abarcando también los otros elementos complejos como son el sexo y el género. Por tal razón la Corte Interamericana de Derechos Humanos postuló su carácter autónomo ${ }^{58}$.

\section{Avances legislativos en torno al reconocimiento del derecho a la identidad de género auto-percibida en México}

Hasta la fecha, son cinco las entidades del país que establecen un procedimiento especial ${ }^{59}$ para garantizar el reconocimiento del derecho a la identidad de género auto-percibida: la Ciudad de México y los Estados de Sinaloa, Nayarit y Michoacán y Coahuila ${ }^{60}$. Cada una, ha precisado reglas para obtener el levantamiento de nueva acta de nacimiento donde sea reconocida su identidad de género auto-percibida, rectificando los datos asentados en el acta de nacimiento primigenia de quien lo solicita, tal como lo hacen diferentes países en el mundo. A continuación se realiza un análisis breve de las disposiciones de referencia.

\section{Ciudad de México}

En el orden local, la Ciudad de México (CDMX) fue la primera entidad del país en hacer patente su compromiso con el colectivo LGBTTTI a través de la publicación de un decreto de reforma en la Gaceta Oficial del gobierno capitalino de fecha 10 de octubre de 2008, mediante el cual se reformaron y adicionaron diversas disposiciones de los códigos civil ${ }^{61} \mathrm{y}$ de procedimientos civiles $^{62}$, ambos para el entonces Distrito Federal.

Con dicha enmienda, la población trans tuvo a su alcance el primer mecanismo para obtener el reconocimiento del derecho a la identidad de género en México, a partir de un procedimiento especial de reasignación para la concordancia sexo-genérica en el Código de Procedimientos Civiles para el entonces Distrito Federal. Por tal motivo, era necesario obtener una resolución favorable de parte de un Juez de lo familiar que ordenará el levantamiento de una nueva acta de nacimiento, modificando el nombre propio y el sexo que aparecían en el acta de nacimiento primigenia; admitiéndose también la posibilidad de contraer matrimonio civil a personas trans, siempre que se diera cumplimiento al requisito de informar al Juez del Registro Civil citadino

57 Galindo Garfias, Ignacio (2010), op. cit., nota 22, pp. 361-362.

${ }^{58}$ El derecho a la identidad y, por tanto, el derecho a la identidad sexual y de género, tiene entre sus implicaciones y alcances más relevantes, el de constituirse como un derecho con carácter autónomo que alimenta su contenido tanto de las normas del derecho internacional, como de aquellas que se deriven de los rasgos culturales propios contemplados en el ordenamiento interno de los Estados. Véase. OC-24/17, p. 46.

59 El Estado de Tlaxcala hace referencia a la posibilidad de obtener la rectificación judicial del sexo o de identidad de la persona en la fracción II del artículo 640 Quinquies (sic) de su código civil, pero sin aludir específicamente a la reasignación de la identidad sexo-genérica.

${ }^{60} \mathrm{El} 28$ de noviembre de 2017 fue presentada ante el Congreso del Estado de Nuevo León una iniciativa de ley sobre el derecho a la libre determinación de la identidad y expresión de género para el Estado de Nuevo León, liderada por el diputado independiente Jorge Alan Blanco Durán, la cual se encuentra actualmente en revisión.

${ }^{61}$ Modificando el contenido de los numerales $2^{\circ}, 35$ y 98, y adicionando el 135 Bis.

${ }^{62}$ Mediante la adición del Capítulo IV Bis al Título Séptimo, compuesto por 10 artículos (498 a 498 Bis 8). 
sobre los antecedentes del sexo del consorte, asegurando de esta forma la confianza que debe prevalecer entre los cónyuges ${ }^{63}$.

Pese al notable avance que significó incorporar este mecanismo, la medida legislativa fue descalificada por grupos y activistas trans, pues adoptaba el criterio patológico de la transexualidad, implicando ajustar la vivencia diversa al binarismo de género a través del uso de tratamientos hormonales avalados por un médico especialista y el dictamen de un psicólogo para corroborar la presencia de la patología ${ }^{64}$. La fuente de tal exigencia reposaba en el DSM-III de 1980 y en la CIE-10 de 1992; sin olvidar que la exigencia de acudir ante una autoridad judicial para obtener el reconocimiento de tal derecho vulneraba el derecho a la intimidad personal.

No obstante lo anterior, gracias al trabajo realizado por defensores y activistas de los derechos del colectivo LGBTTTI en México y todo el mundo, el pasado 19 de junio de 2018 la OMS suprimió de la Clasificación Estadística Internacional de Enfermedades (CIE-11) al transexualismo para dejar de considerarlo un trastorno de la identidad sexual ${ }^{65} \mathrm{y}$, por ende, una patología como ocurría en la versión pasada. De este modo, ahora se trata de una condición relativa a la salud sexual, definiéndola como una incongruencia de género ${ }^{66}$; situación que disuelve poco a poco la versión fundada en estereotipos rígidos de conducta como condición de la naturaleza humana ${ }^{67}$.

Siguiendo el hilo conductor de esta tendencia progresista sobre los derechos humanos de personas trans, en el año 2015, los legisladores citadinos sustituyeron el procedimiento especial judicial por uno de naturaleza administrativa seguido ante el Juez del Registro Civil a través de una reforma realizada al citado código civil de la Ciudad de México ${ }^{68}$. Más tarde, la autoridad administrativa competente hizo lo propio al incluir el procedimiento correspondiente en el Reglamento del Registro Civil ${ }^{69}$ de la $\mathrm{CDMX}^{70}$. Con estas medidas se lograron dos cosas: la adopción del criterio no patológico de las vivencias trans y, la desjudicialización del procedimiento.

De esta forma, el gobierno citadino dio un paso importante en la construcción de una sociedad más incluyente, de acuerdo con lo expresado en la opinión consultiva OC-24/17 de la Corte Interamericana de Derechos Humanos de 24 de noviembre de 2017 tras una solicitud presentada por Costa Rica el 18 de mayo de 2016, en la cual se clarificó el alcance de los artículos 11.2 (protección de la honra y la dignidad), 18 (relativo al derecho al nombre) y 24 (relativo a la igualdad ante la ley) de la Convención Americana de Derechos Humanos; criterio esencial

\footnotetext{
${ }^{63}$ Recordemos que la fracción VII del artículo 98 del código civil para el Distrito Federal (hoy CDMX) fue adicionada a fin de que el consorte que haya obtenido el reconocimiento estatal del derecho a la identidad de género auto-percibida informe al Juez del Registro Civil de esta circunstancia a través de una declaración por escrito y bajo protesta de decir la verdad.

${ }^{64}$ La fracción III del artículo 498 Bis de la legislación adjetiva civil para la Ciudad de México, exige presentar dos dictámenes expedidos por dos profesionistas con experiencia clínica en procedimientos de reasignación de identidad de género.

65 Véase. Agencia de noticias de Francia (2018), Transexualidad ya no es enfermedad mental: OMS, La Jornada, 19 junio, [en línea], disponible en: http://www.jornada.com.mx/ultimas/2018/o6/19/transexualidad-ya-no-esenfermedad-mental-oms-166.html (consultada el 5 de diciembre de 2018).

${ }^{66}$ El documento de referencia señala que la incongruencia de género se caracteriza por una marcada y persistente incongruencia entre el género experimentado de un individuo y el sexo asignado. Las variantes en el comportamiento y las preferencias por sí solas no son una base para asignar los diagnósticos en este grupo.

${ }^{67}$ Esta nueva clasificación entrará en vigor a partir del o1 de enero de 2022.

68 Publicada en la Gaceta Oficial del Gobierno de la Ciudad el o5 de febrero de 2015.

${ }^{69}$ Mediante la adición del apartado denominado "De las actas nacimiento [sic] derivadas del procedimiento administrativo de identidad de género”, compuesto por tres artículos (69 Ter, 69 Quater y 69 quinquies [sic]).

70 Publicada en la Gaceta Oficial del Gobierno de la Ciudad el 14 de octubre de 2015.
} 
para que el resto de estados americanos adopten una política equivalente para resolver casos similares.

Este precedente constituye un punto de partida muy importante en la región, ya que establece estándares mínimos para que los Estados dicten medidas legislativas tendientes a favorecer el reconocimiento y protección de los derechos de las personas trans; como ya se había pronunciado la Asamblea General de la Organización de los Estados Americanos (OEA) desde el año 2008, al dictar varias resoluciones importantes en torno a este asunto ${ }^{71}$; obligatorias para el Estado mexicano en virtud de la aplicación del sistema de control de convencionalidad adoptado por la Constitución Política de los Estados Unidos Mexicanos a partir de la reforma publicada en el Diario Oficial de la Federación el 10 de junio de 2011.

\section{Sinaloa}

La segunda entidad del país en reconocer el derecho a la identidad de género por la vía judicial fue el Estado de Sinaloa. El artículo 1193 in fine del Código Familiar del Estado ${ }^{72}$, garantiza el derecho para que aquéllas personas que desean concordar la identidad de género auto-percibida con el sexo y nombre que aparecen en el acta de nacimiento primigenia, puedan acudir ante un Juez de lo familiar a solicitarlo de conformidad con el procedimiento al que se refiere el Libro Tercero, Capítulo VII del código adjetivo de la misma materia ${ }^{73}$.

Del mismo modo en que se tramitaba el juicio especial para la concordancia sexo-genérica en la Ciudad de México antes de la reforma de 05 de febrero de 2015, el Código de Procedimientos Familiares del Estado también establece como requisito presentar dos dictámenes realizados por profesionistas con experiencia en procesos de tal naturaleza ${ }^{74}$, recogiendo el criterio patológico de las vivencias trans; esto a pesar de la recomendación planteada por la Comisión Interamericana de Derechos Humanos en el Informe sobre violencia contra personas LGBTI de $2015^{75}$, para que México adopte medidas legislativas tendientes a reconocer este derecho en todo el territorio nacional.

Por lo anterior, si bien esta medida legislativa supuso un acierto importante en un momento histórico concreto, actualmente ya no tiene cabida pues la tendencia promovida por organismos internacionales consiste en velar por el respeto de la dignidad y protección de los derechos de la población trans en todo el mundo; como consecuencia de lo anterior, este procedimiento deberá ser modificado por los legisladores locales en los próximos años.

\footnotetext{
${ }^{71}$ Mediante la suscripción de las AG/RES. 2435 (XXXVIII-O/o8) sobre derechos humanos, orientación sexual e identidad de género; AG/RES. 2653 (XLI-O/11) sobre derechos humanos, orientación sexual e identidad de género; AG/RES. 2721 (XLII-O/12) sobre derechos humanos, orientación sexual e identidad de género; AG/RES. 2807 (XLIII-O/13) sobre derechos humanos, orientación sexual e identidad y rol de género, todas tendientes a favorecer un trato respetuoso y digno de los derechos humanos de esta minoría de personas y AG/RES. 2863 (XLIV-o/14) sobre derechos humanos, orientación sexual e identidad y expresión de género.

72 Publicado en el Periódico Oficial de la entidad el o6 de febrero de 2013.

73 Publicado en el Periódico Oficial de la entidad el 22 de noviembre de 2013.

${ }^{74}$ Según se desprende del contenido del artículo 435, fracción III en relación con el 438 del código de referencia.

75 En el rubro "Recomendaciones al Poder Legislativo", numeral 26, la CIDH recomienda: Adoptar leyes de identidad de género que reconozcan el derecho de las personas trans a rectificar su nombre y el componente sexo en sus certificados de nacimiento, documentos de identidad y demás documentos legales, a través de procesos expeditos $y$ sencillos, y sin que sea necesario que presenten evaluaciones o certificados médicos o psicológicos/psiquiátricos.
} 


\section{Nayarit}

El Estado de Nayarit es otro de los territorios del país que se ha adherido a la tendencia progresista que vela por la protección de las disidencias de sexo y género. Primero al admitir relaciones de hecho y matrimonio civil por personas del mismo sexo, a partir de la modificación de los artículos 135 y 136 del código civil del Estado de Nayarit en $2015^{76}$, y después, al adicionar el procedimiento administrativo para obtener nueva acta de nacimiento donde se reconozca el derecho a la identidad de género auto-percibida ante un Oficial del Registro Civil77, con la publicación del decreto de reforma de 27 de julio de 2017 mediante el cual se adicionaron algunas disposiciones al código civil de la entidad, particularmente, los artículos 36, 130, 131, fracción III; 131 Bis, 131 Ter y 131 Quater (sic).

Al igual que la regulación de la Ciudad de México, la del Estado de Nayarit también adoptó el criterio no patológico de las vivencias trans, ya que no se exige presentar ningún documento que avale acudir a terapias, tratamientos hormonales o cirugías de reasignación para conseguir el reconocimiento de este derecho, pudiéndose tramitar ante la Dirección Estatal del Registro Civil o directamente ante la Oficina del Registro Civil donde se haya levantado la partida de nacimiento primigenia de la persona interesada; lugar al que deberá comparecerse tras la revisión y cotejo de los documentos a los que se refiere el artículo $131 \mathrm{Ter}^{78}$ del referido código en relación con lo dispuesto en numeral 192 del Reglamento del Registro Civil de la misma entidad79.

No obstante lo anterior, es pertinente comentar que resulta confusa la redacción de la fracción III del artículo 131 al emplear el verbo variar en lugar de reasignar, ya que no se varía la identidad jurídica de una persona, en todo caso, lo que se produce es la reasignación del sexo asentado en el acta de nacimiento primigenia ${ }^{80}$, pues al ser este un derecho de la personalidad, entendido como una mera posibilidad abstracta, para actuar como sujeto activo o pasivo, en la infinita gama de relaciones jurídicas que pueden presentarse, la identidad posee un carácter único, indiviso y abstracto ${ }^{81}$.

\footnotetext{
${ }^{76}$ Mediante un decreto de reforma publicado en el Periódico Oficial del Estado, el 22 de diciembre de 2015.

77 Publicado en el Periódico Oficial ese mismo día.

${ }^{78}$ Artículo 131 Ter.- Para realizar el levantamiento de una nueva acta de nacimiento para el reconocimiento de identidad de género las personas interesadas deberán presentar:

I. Solicitud debidamente requisitada;

II. Copia certificada del acta de nacimiento primigenia para efecto de que se haga la reserva correspondiente;

III. Original y copia fotostática de su identificación oficial, y

IV. Comprobante de domicilio...

${ }^{79}$ Artículo 192.- Para la autorización de la rectificación de acta que deba registrarse por identidad de género, en términos de Código Civil, los interesados deberán cumplir los siguientes requisitos:

I. Ser de nacionalidad mexicana;

II. Ser mayor de edad;

III. Presentar solicitud debidamente requisitada;

IV. Presentar copia certificada del acta de nacimiento primigenia para el efecto de que se haga la reserva correspondiente;

V. Presentar original y copia fotostática simple de su identificación oficial;

VI. Presentar comprobante de domicilio;

VII. El nombre completo y los datos registrales asentados asentados en el acta primigenia, y

VIII. Deberá manifestar el nombre solicitado sin apellidos y, en su caso, el género solicitado.

${ }^{80}$ Artículo 131.- Ha lugar a pedir la rectificación o modificación:

... III. Para variar el sexo y la identidad de la persona, en el ejercicio al libre desarrollo de la personalidad. ...

(las cursivas son del autor).

${ }^{81}$ Galindo Garfias, Ignacio, (2010), op cit., nota 22, p. 307. 


\section{Michoacán}

La cuarta entidad del país en prever un procedimiento administrativo para obtener el reconocimiento de este derecho es Michoacán, mediante la publicación en el Periódico Oficial de una reforma al artículo 117 del Código Familiar de dicha entidad el 18 de agosto de 2017. Sin olvidar que, Michoacán al igual que la Ciudad de México, también admite el matrimonio civil a parejas del mismo sexo en el artículo 127 del mismo cuerpo legal desde el año $2016^{82}$.

La normatividad de esta otra entidad tampoco exige ninguna terapia psicológica, tratamiento hormonal o cirugía de reasignación genital para obtener el reconocimiento de la identidad de género auto-percibida, según lo dispuesto en el artículo 117 del citado cuerpo legal, acogiendo el criterio no patológico de las vivencias trans.

\section{Coahuila}

La más reciente entidad en reconocer este derecho es Coahuila ${ }^{83}$, al adicionar en las Leyes Familiar y del Registro Civil del Estado, un procedimiento administrativo como el que aparece en las dos anteriores, el cual tampoco exige ningún peritaje para acreditar el estado transexual verdadero, pues también adopta el criterio no patológico. En la parte sustantiva, al incluir el artículo 133 y, en la parte adjetiva, añadiendo la Sección Cuarta relativa al procedimiento que consta de cinco artículos ${ }^{84}$, ambas publicadas en el Periódico Oficial de la entidad el 27 de noviembre de $2018^{85}$, sumándose a la tendencia instaurada en las entidades antes referidas.

Si bien las medidas legislativas descritas son un esfuerzo importante para garantizar los derechos humanos de la población trans, aún quedan diversos aspectos pendientes en la agenda política nacional para establecer un trato digno y visibilizar a estas personas en la esfera social, especialmente durante el tránsito de la niñez y adolescencia, ya que es en estos primeros estadios del desarrollo psico-social cuando se define la identidad de género del individuo; situación que ha motivado a otros países latinoamericanos y europeos a legislar en esta materia. En este sentido es llamativo el caso de Luana, una niña trans que obtuvo el reconocimiento del derecho a la identidad de género auto-percibida en el año 2013, con base en el principio de la autonomía progresiva de la infancia previsto en la Convención sobre los Derechos del Niño de 1989, la Ley de Identidad de Género y el Código Civil y Comercial argentinos; historia narrada vehementemente por la madre de Luana, la señora Gabriela Mansilla, en el libro titulado: Yo nena, yo princesa: Luana la niña que eligió su propio nombre ${ }^{86}$, que ha servido para que otros países del mundo, entre ellos México, hayan reconocido este derecho a menores de edad a pesar del vacío legal ${ }^{87}$.

${ }^{82}$ Reforma publicada en el Periódico Oficial del Estado el 22 de junio de 2016.

${ }^{83}$ En un comunicado de prensa del gobierno del Estado, se informó que ese mismo día se realizó el primer procedimiento, estando pendientes otros 15 casos.

${ }^{84}$ Del artículo 124 al 128.

${ }^{85}$ Disposiciones que entraron en vigor el pasado 22 de febrero de 2019.

${ }^{86}$ Véase. Mansilla, Gabriela (2014), Yo nena, yo princesa: Luana, la niña que eligió su propio nombre, Buenos Aires, Argentina, Universidad Nacional de General Sarmiento.

${ }^{87}$ En fechas recientes la Oficina del Registro Civil de la Ciudad de México, reconoció el derecho a la identidad de género a una niña trans de nombre Sophía a pesar del vacío legal existente en la Ciudad de México. Al respecto, se recomienda. Agencia de Noticias Internacional (2017), "Sophía, la niña 'trans' que hace historia en México", Excélsior, 16 de octubre, [en línea], disponible en: https://www.excelsior.com.mx/nacional/2017/10/16/1194979 (consultada el 03 de enero de 2019). 


\section{Comentarios finales}

Durante la segunda mitad del siglo XX se registro un avance vertiginoso en el campo de la endocrinología y de las intervenciones de reasignación genital, suscitando el inicio del período de medicalización transexual, según el cual, esta vivencia es una enfermedad que debe ser tratada y corregida. Con el transcurso de los años el activismo, los estudios post-feministas y la contribución de las ciencias sociales gestadas en las décadas de los ochenta y noventa centraron su atención en el tema, cuestionando la descripción binaria del sexo y el género postulando su despatologización. A ello responde que en los últimos años, los criterios judiciales y ciertas normativas de derecho comparado tomaran un rumbo distinto.

Los derechos al libre desarrollo de la personalidad y a la identidad son derechos que, al ser la esencia misma de la persona en su calidad de ser humano, permiten al individuo elegir en forma libre y autónoma el proyecto de vida que se desee para ser uno mismo y ejercer libremente la capacidad del autoconocimiento integral, siempre al margen del sistema jurídico. Sin su reconocimiento, se coartaría la libertad para que cualquier persona fuera artífice de su propio destino, pudiendo construir una biografía única e irrepetible.

$\mathrm{Al}$ adherir el factor psico-social a la definición del sexo, se comprendió el papel que ocupa el elemento interno en la construcción de la identidad de género, concebida por los Principios de Yogyakarta como la vivencia interna e individual del género tal como cada persona la siente profundamente, la cual podría corresponder o no con el sexo asignado al momento del nacimiento, incluyendo la vivencia personal del cuerpo y otras expresiones de género, incluyendo la vestimenta, el modo de hablar y los modales.

La promulgación de la Ley No. 26743 de Identidad de Género en Argentina marcó un hito mundial en la forma de abordar el tema desde el plano normativo; también influyó en la elaboración de ciertas disposiciones jurídicas para obtener el reconocimiento del derecho a la identidad de género en algunas entidades del país con base en la tendencia garantista instaurada por la SCJN en el reconocimiento de los derechos humanos de la población trans con base en los Principios de Yogyakarta de 2006, las resoluciones emitidas por la OEA y, la opinión consultiva OC-24/17 de la CIDH de 24 de noviembre de 2017.

Si bien, todas las medidas descritas han sido fructíferas para garantizar los derechos humanos de esta población, aún quedan diversos aspectos pendientes en la agenda política nacional para tratar con respeto y dignidad a estas personas en las esferas pública y privada, especialmente en el tránsito entre la niñez y la adolescencia.

\section{Fuentes de consulta}

Agencia de noticias de Francia (2018): Transexualidad ya no es enfermedad mental: OMS, en La Jornada [en línea], disponible en: http://www.jornada.com.mx/ultimas/2018/o6/19/ transexualidad-ya-no-es-enfermedad-mental-oms-166.html

Agencia de Noticias Internacional (2017): Sophía, la niña trans que hace historia en México, en Excélsior [en línea], disponible en: https://www.excelsior.com.mx/nacional/2017/10/16/1194979

Aparisi Miralles, Ángela (2011), “Derecho a la identidad (jurídico)”, en: Romeo Casabona, Carlos María (Dir.), Enciclopedia de Bioderecho y Bioética, España, Comares, t. I (a-h). 
Araneta Zinhunegi, Aitzole (2017), “Transfronteras: un nuevo activismo mundial por la despatologización trans”, en: Moreno Cabrera, Octavio y Puche Cabezas, Luis (eds.), Transexualidad, adolescencias y educación: miradas multidisciplinares, 2a. ed. Madrid, España, Egales, pp. 89-109.

Benjamin, Harry (1999), The transsexual phenomenon, Symposium publishing, Düsseldorf.

Camps Merlo, Marina (2007), Identidad sexual y derecho. Estudio interdisciplinario del transexualismo, España, EUNSA.

Cauldwell, David O. (1966), Trasvestismo. Hombres vestidos de mujer, trad. de Luis F. Rodríguez Molina, s.l.i. Manuales científicos.

Comisión Interamericana de Derechos Humanos (2015), Violencia contra personas Lesbianas, Gay, Bisexuales, Trans e Intersex en América, s.l.e. CIDH.

Fernández Sessarego, Carlos (1992), Derecho a la identidad personal, Buenos Aires, Argentina, Astrea.

Frignet, Henry (2003), El transexualismo, trad. de Horacio Pons, Argentina, Nueva visión.

Galindo Garfias, Ignacio (2010), Derecho civil, 27a. ed. México, Porrúa, p. 788.

Helien, Adrián y Piotto, Alba (2012), Cuerpxs equivocadxs: hacia la comprensión de la diversidad sexual, Argentina, Paidós.

Junyent Bas de Sandoval, Beatriz María (2016), Fecundación asistida e identidad personal, Buenos Aires, Argentina, Astrea.

Kemelmajer de Carlucci, Aída y Lamm, Eleonora (2010), "La persona transexual, menor de edad competente para decidir sobre la intervención médica que requiere judicialmente”, en: Diversidad sexual, Argentina, Lugar-APA, pp. 183-203.

Lamas, Marta (2014), Cuerpo, sexo y política, México, Océano-Debate feminista.

Lamas, Marta (2012), “Transexualidad: ¿el estudio de lo extraño?”, en Parrini Roses, Rodrigo (coord.), Los archivos del cuerpo: ¿Cómo estudiar el cuerpo?, México, UNAM, Programa Universitario de Estudios de Género, pp. 211-233

Lameiras Fernández, María et. al. (2013), Sexualidad y salud: el estudio de la sexualidad humana desde una perspectiva de género, España, Universidad de Vigo-Servizo de Publicacións.

López Serna, Marcela Leticia y Kala, Julio César (2018), "Derecho a la identidad personal, como resultado del libre desarrollo de la personalidad”, Revista Ciencia Jurídica, México, año 7, núm. 14, pp. 65-76.

Lozano Villegas, Germán (2004), "El libre desarrollo de la personalidad y cambio de sexo: el transexualismo", en: Carbonell, Miguel (Coord.), Derecho constitucional. Memoria del 
Congreso Internacional de Culturas y Sistemas Jurídicos Comparados, México, UNAM, Instituto de Investigaciones Jurídicas. pp. 619-637.

Mansilla, Gabriela (2014), Yo nena, yo princesa: Luana, la niña que eligió su propio nombre, Buenos Aires, Argentina, Universidad Nacional de General Sarmiento.

Menin, Francisco J. (2015), "La identidad de género como derecho humano: la legislación argentina”, Anuario de Derecho Constitucional, Colombia, año XXI, pp. 627-641.

Mercader, Patricia (1997), La ilusión transexual, trad. de Paula Mahler, Argentina, Nueva visión.

Missé, Miquel (2014), Transexualidades. Otras miradas posibles, Madrid, España, Egales.

Money, John y Ehrhardt, Anke A. (1982), Desarrollo de la sexualidad humana. diferenciación y dimorfismo de la identidad de género desde la concepción hasta la madurez, trad. de A. Guerra Miralles, España, Morata.

NúÑez Noriega, Guillermo (2016), ¿Qué es la diversidad sexual?, México, Ariel-CIADUNAM, Programa Universitario de Estudios de Género.

Saldivia Menajovsky, Laura (2017), Subordinaciones invertidas: sobre el derecho a la identidad de género, México, UNGS-UNAM, Instituto de Investigaciones Jurídicas.

(2018), "La bioética despatologizadora del derecho a la identidad de género", en: Bioética laica: vida, muerte, género, reproducción y familia, México, UNAM, Instituto de Investigaciones Jurídicas, pp. 137-153.

VÁsquez Mellado García, Julio César (2017), "Nueva acta de nacimiento: un derecho de las minorías (transexuales)”, en: Valls Esponda, Guillermo y Valls Esponda, Sergio Arturo (Coords.), Tiempo de justicia: voces responsables: estudios en homenaje a Sergio Valls Hernández, México, SCJN, pp. 1033-1061. 